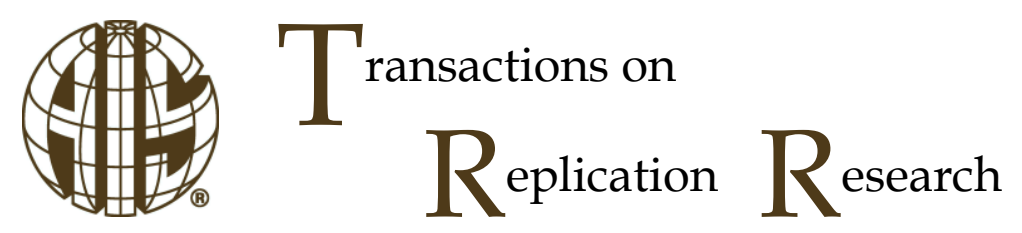

\title{
Switching to Electronic Health Record Systems: A Replication of the User Resistance Model
}

\author{
Bahae Samhan \\ Accounting and BIS Department \\ Illinois State University \\ bmsamha@ilstu.edu
}

\author{
KD Joshi \\ Department of Information Systems \\ University of Nevada Reno \\ kjoshi@unr.edu
}

\begin{abstract}
:
The purpose of this conceptual replication study is to understand the resistance construct of the User Resistance Model (URM) in the context of Health Information Technology (HIT) at an international healthcare organization. Specifically, we studied resistance towards Electronic Health Record systems (EHR). For this, the original scale items were adapted to the new context, and the model was tested with the data collected from 226 employees who work with an EHR system at a large public hospital in Amman, Jordan. Overall, the results support six of the eleven posited hypotheses. One hypothesis was contradicted, and the remaining four hypotheses were not supported. Moreover, the model fit statistics suggested that the current URM does not have a good fit. This indicates that the URM in the new context needs further investigation. We first discuss the hypotheses that are not supported or contradicted and then begin to suggest refinements to the model in an effort to improve its fit.
\end{abstract}

Keywords: Electronic Health Records (EHR), Electronic Medical Records (EMR), Health Information Technology (HIT), Replication Research, Resistance, Structural Equation Modeling (SEM), User Resistance Model (URM).

The manuscript was received 10/17/2018 and was with the authors 8 months for 2 revisions. 


\section{Introduction}

Electronic Health Records (EHR) are expected to bring a number of benefits to healthcare organizations. EHR can increase patient safety, reduce cost of healthcare delivery, and improve efficiency in the healthcare industry (NITRD, 2004; Hillestad et al., 2005). Despite the benefits, full use of health information technologies (HIT) in general (Romanow et al., 2011) and EHR in particular (Sheikh et al., 2011) remains a challenge. In 2009, it was estimated that $73 \%$ of the hospitals are "not using the system as intended 12 months after implementation" (Terry, 2012). Case studies conducted in 2013 suggest that such struggles with the use of EHR systems are evident globally (Stone, 2014). In a more recent study, Kruse et al. (2016) found that roughly one in four hospitals does not have even a basic EHR system due to resistance issues. Similarly, Akhu-Zaheya et al. (2018) found the many hospitals are still using paper-based recording systems.

The slow progress in achieving the true benefits of EHR systems is, at least in part, attributed to healthcare providers' reluctance to change to new ways of working (Nov and Schecter, 2012; Samhan and Joshi, 2015). Our understanding of why healthcare providers are unwilling to switch to new ways of working with the use of EHR systems is still in its incipient stage. Most of the EHR studies that examine this phenomenon conceptualize it using the system adoption lens to uncover the factors that either encourage or discourage adoption of EHR systems. We argue that while this perspective is helpful, it does not fully explain why individuals do not want to change to the new ways of working with EHR systems. A few studies that have tried to capture behaviors such as resistance to EHR systems are mostly either conceptual (Boonstra and Broekhusi, 2010; Najaftorkaman et al., 2015; Vishwanath and Scamurra, 2007) or qualitative (Angst and Agarwal, 2009; Ngafeeson and Midha, 2014; Reardon and Davidson, 2007). As a result, there is an evident lack of empirically tested models that explain healthcare providers' resistance to EHR systems (Boonstra and Broekhuis, 2010; Weeger et al., 2011; Olaniran, 2015, Samhan and Joshi, 2015).

Prior research examined parts of the URM in the healthcare context but with no aim to fully replicate the theory in this new context (e.g., Hsieh, 2015). Additionally, few studies have aimed at capturing resistance at the post-implementation stage (e.g., Hsieh and Lin, 2018), however, limited work is found on examining resistance towards EHR at the post implementation stages.

In this study, we capture healthcare providers' perceptions toward switching from a Paper-Based Recording System (PBRS) to a new EHR system to model the factors that shape resistance at early stages of the EHR implementation.

Examining resistance towards HIT requires special attention to the unique context of healthcare organizations. In a healthcare organization, physicians enjoy higher levels of freedom of choice and less managerial control over their HIT use/resistance decisions. This is partially because they are seldom employed by the hospital (Halamka, 2011). Additionally, healthcare providers often perceive the use of some technologies as unnecessary hurdles that prevent them from performing their duties of providing care to patients (Cotea, 2010; Sassen, 2009). Therefore, resisting the use of HIT is viewed as championing the cause for better patient care. Furthermore, healthcare providers perceive the interaction with HIT as an activity that is not part of their "job description" and thus they are not willing to stretch their capacities to perform nonmedical tasks (Buchbinder and Shanks, 2016). Many consider the use of HIT as inappropriate for the physicians because it requires "clerical tasks" that undermine their professional status (Lapointe and Rivard, 2005).

This study is a conceptual replication of the study of the User Resistance Model (URM) by Kim and Kankanhalli (2009), which explored resistance to change associated with the implementation of a new IS system. The URM studied resistance towards a system that was about to be implemented, while in this study we are exploring resistance after the EHR system has been fully implemented. To our knowledge, this work is the first attempt in the IS literature to conceptually replicate a comprehensive theoretically grounded model to examine resistance to EHR systems.

The paper makes several contributions to practice and theory. First, the replication helps in strengthening theory on technology resistance by examining the original research model in a different environment (Dennis and Valacich, 2014; Tsang and Kwan, 1999). Second, the replication suggests that the constructs of the URM are relevant in the new environment while being aware of the healthcare-specific contextual considerations. Third, our study contributes to bridging the IS research gap existing between developed and developing nations (Asamoah et al., 2015). Understanding technology resistance in developing countries sheds light on a new and significantly different context to most existing studies (Roztocki and Weistroffer, 2009, 2011). 
The remainder of the paper is organized as follows. Section 2 describes the URM in its original study. Section 3 summarizes the investigative context for this study. Section 4 explains the methodological approach used for this study. We posit our results in section 5 and discuss model fit findings in section 6 . Finally, we provide our contributions and discuss the limitations of this study in sections 7 and 8 , respectively.

\section{The URM}

The URM is a comprehensive framework, which integrates multiple theories in an aim to explain user resistance prior to the technology implementation stage. Namely it integrates the Equity Implementation Model (EIM) (Joshi, 1991), the Status Quo Bias Theory (SQBT) (Samuelson and Zekhauser, 1988), and the Theory of Planned Behavior (TPB) (Ajzen, 1991). It explains user resistance to new technology prior to the implementation of the system.

In the original study, the URM was tested using data collected from a major IT service company that is deploying a new enterprise system called "New Office Plus" (NOP). NOP is a "combination of an enterprise portal and knowledge management system. It serves several key functions, such as enterprise-wide communication and task processing, collaboration with colleagues, personal scheduling, and knowledge management" (Kim and Kankanhalli, 2009, p. 574).

Data were collected from the employees during the last five days before the NOP was put into operation. They collected data using survey questioners as well as conducting interviews with users and the project manager. They collected a total of 202 valid responses from employees at different positions (108 frontline employees, 82 middle managers, and 12 managers) across 10 business units (finance, human resource, procurement, research, consulting, manufacturing business, financial business, public business, IT solution, and training center) (Kim and Kankanhalli, 2009, p. 575).

The URM in the original study highlighted the significance of switching costs as a key determinant of user resistance. It also identifies colleague opinion and self-efficacy for change as antecedents that reduce switching costs. It indicates the role of the perceived value of the technology and organizational support as factors reducing user resistance. Figure 1 illustrates the results from testing the URM model in the original study. The original study also included four control variables (gender, age, tenure, and position) but none of them had a significant effect on user resistance.

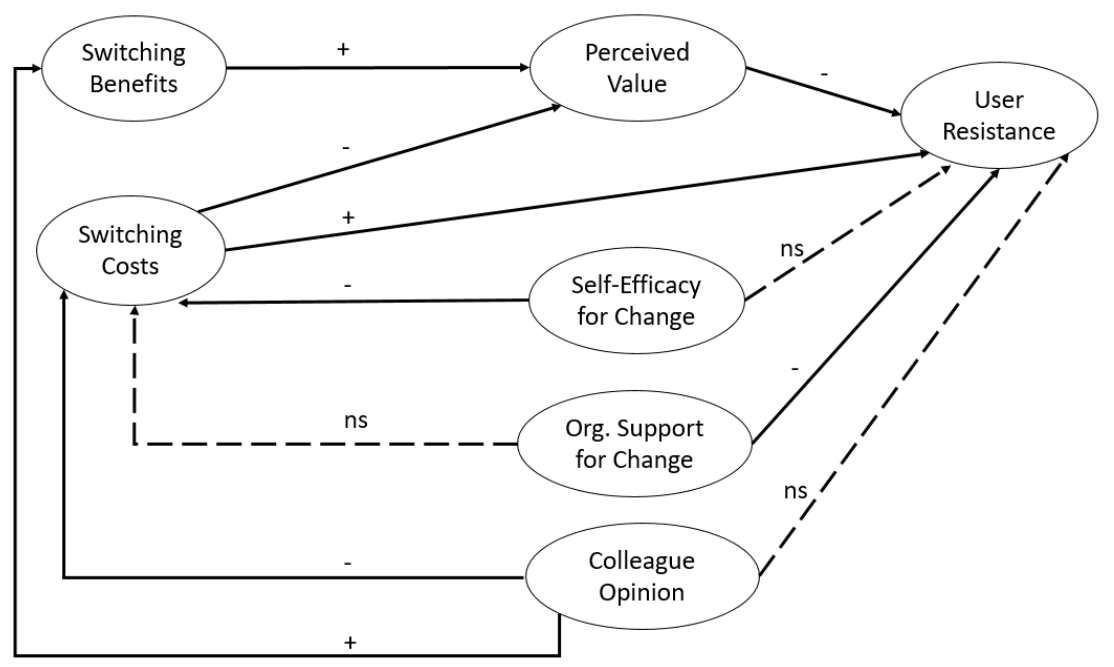

Figure 1. URM (Kim and Kankanhalli, 2009)

The URM was developed in the original study to examine resistance towards enterprise portals and knowledge management systems prior to their implementation in an IT service organization. In our study, we use data from a large international public hospital to assess resistance to change from Paper-Based Recording System (PBRS) to EHR. The study uses the same hypotheses as the URM but with different measures and treatments suitable for the new context of the study. The wording of the scale items measuring key constructs are altered to fit the healthcare context. Additionally, this study explores resistance towards a different type of software (an EHR system), and at a different stage of its 
implementation. The URM studied resistance towards a system that was about to be implemented, while in this study we are exploring resistance after the EHR system has been fully implemented.

\section{Investigative Context}

The target hospital for this study is a large public governmental hospital located in Amman, the capital city of the Jordanian kingdom. The hospital consists of multiple health departments and 33 specialists' clinics. The total in-patient capacity, at the time of the study, is 450 beds. The hospital has implemented a new EHR system that is mandated for all employees. It is one of two health organizations in the country that have completely implemented the system.

The new EHR system is named "Hakeem", the Arabic word for "Doctor." Hakeem was implemented through a governmental program, which is the first national e-health initiative in Jordan. The system was designed and implemented by Electronic Health Solutions (EHS), which is a non-profit, innovative, technology-driven company established in early 2009. EHS is a partnership between the main healthcare stakeholders: Ministry of Health, Ministry of Information and Communications Technology, Royal Medical Health Awareness Society and Private Hospitals Association.

According to EHS, 4.5 million Jordanian Dinars (around $\$ 6.4$ million) were invested in specialized resources to develop and implement Hakeem. Hakeem is a combination of an informational portal and a transactional system. It serves several key functions, such as storage, retrieval and updating of the EHR of patients cared for by all of the participating healthcare facilities in Jordan. Implementation of Hakeem brought substantial changes to the organization in terms of how employees perform their tasks. Employees had to switch from using the familiar previous paper-based system to the new system, Hakeem. When entering data into the system, employees are required to complete the data entry of each field in the form before being able to move to the next page. This is perceived, in some cases, to be unnecessary and time-consuming. In addition, the system is only accessible from specific computers that are located within the hospital.

The project started in 2009, was implemented in 2014, and was enforced early 2015 . During the transition time between the implementation and the enforcement of the system, both PBRS and the new EHR system were used at the hospital. However, after the system has been enforced, paper records were no longer used at the hospital. In this study, resistance is measured as negative attitudes toward the system; therefore, users can have high levels on the scale related to user resistance. These negative attitudes could be turned into resistance by performing rejecting behaviors towards the new EHR system. In a healthcare organization, physicians enjoy higher levels of freedom of choice and less managerial control over their HIT use/resistance decisions. This is partially because they are seldom employed by the hospital (Halamka, 2011). Therefore, EHR resistance would be manifested as a rejection to use the newly implemented EHR system.

In this study, we attempt to adopt the URM in the context of healthcare. Specifically, we explore resistance towards EHR at a different stage of its implementation. The URM studied resistance towards a system that was about to be implemented, while in this study we are exploring resistance after the EHR system has been fully implemented.

The URM was selected for this study for many reasons. First, the URM explain resistance to change associated with the implementation of a new IS system. Our theoretical development focuses on the early implementation stage of the EHR system. In this stage, the hospital is keeping both the old PBRS and the new EHR system in place, and employees are gradually changing from the PBRS to the EHR. In a later stage, the EHR system will be mandated to all employees and the PBRS will no longer be available for them to use. In the context of our study, we aim to capture the resistance reported by employees when changing from the PBRS to the EHR system. Second, the URM integrates different perspectives of user resistance including the SQBT, which will help explaining employees' resistance to change due to the preference to stay with the status of working with the PBRS. Additionally, the URM includes the EIM perspective, which will help in explaining employees' resistance to change to the EHR system based on cost-benefit analysis of the change or the "net equity" associated with the change to the new EHR system. Third, the URM is a comprehensive model, which draws from previous literature various antecedents for technology acceptance and resistance. Which allows us to integrate concepts from the technology acceptance literature including attitude, subjective norms, and behavioral control (Ajzen, 1991). Fourth, prior research that tested the URM on EHR systems were not found in the IS literature. Finally, replicating the URM in a different context for 
the first time will help in making findings more generalizable and will contribute to the progress of research in this area. Nosek et al (2015) reported that research progress relies on both innovations that points out possible paths, and replication that points out likely paths. Thus, this work will increase certainty when findings are reproduced, and promote innovation when they are not.

We believe that measuring resistance antecedents post EHR implementation will provide us with a different perspective of user resistance. This study provides an understanding on how users perceive the value in changing to the new way of working with the system after it has been fully implemented. Unlike the original study, users' decisions in this study are made based on actual experience of interacting with the new system. This includes their perceptions of cost, benefits, and self-efficacy. Additionally, social influence can be different at different stages of implementation. In this study, informed users who have experienced working with the system are the source of social influence. Furthermore, organizational support in our study indicates levels of support the hospital has provided to employees in an attempt to facilitate using the new system. In the original study, organizational support is limited to the guidance provided by the organization on how employees can change to the new system. This may explain why organizational support had no significant effect on switching cost in the original study.

In addition to assessing key variables of URM in this study, we included several demographic control variables. First, we controlled for the position at the hospital because it is argued that employees with different positions would perceive the change differently (Lapointe and Rivard, 2005). Second, we control for the number of employees in a unit at the hospital because social influence can influence different types of behavior such as resistance (Cialdini and Goldstein, 2004). Third, we controlled for age, gender, and level of education to assess how individual differences may affect their resistance.

\section{Methodology}

\subsection{Instrument Development}

Existing validated scales were adopted for this study. We mainly adopted the instrument items used for the URM's original study. However, all items were modified to fit the context of our study. No translation of questionnaire items was necessary. Measurement items were anchored on five-point Likert scales $(1=$ strongly disagree, 5 = strongly agree). The instrument was reviewed by IS researchers before the study. The final version of the questionnaire developed for the main study is shown in Table A1 of the appendix.

\subsection{Sample and Data Collection}

The total estimated number of employees who work at the hospital is 5,500. The majority of these employees are potential users of the new system. Administrative staff are less likely to use the system, as they do not participate in the care-giving process, but they still have access to the system and would be able to print out reports as needed. The sample is a combination of all stakeholders of the system (i.e., physicians, nurses, lab specialists, radiologists, pharmacists, admin staff, and resident medical students). Data were collected in two phases: a pilot study and a main study. Data were collected few months after the system has been mandated at the hospital and the PBRS was no longer in use. At this stage, users begin to shape strong beliefs and attitudes towards the system since they are no alternatives.

\subsubsection{The Pilot Study}

In the first phase, we collected data for the pilot study from employees who work only for the Dermatology unit at the hospital. We collected a total of 126 responses. After conducting Exploratory Factor Analysis (EFA) and Confirmatory Factor Analysis (CFA) of the data collected for the pilot test, it was necessary to alter some of the items to address a few issues related to the psychometric properties of factors. Additionally, some new items were added to better capture the concepts of some constructs, these items are PVL4, SOI4, OGS4, and SFC4 in table A1 in the appendix.

First, SWC1 had a low loading of 0.451 . The item is developed to capture sunk costs, which refers to the investments and costs already put into mastering the current way of working (Kim, 2011). Thus, it was necessary to reword the item to reflect the costs healthcare providers have invested in the previous PBRS, so we added "I already have" at the beginning of the survey question. The loading of the item went up to 0.702 after collecting data for the main study. Second, SFC1 also had a low loading of 0.595 . The item was reworded to match other factors of the same construct. This resulted in an increase in its loading in the main 
study to become 0.761 . Additionally, we added item SFC4 into the main study survey to capture the levels of confidence healthcare providers have in their ability to change to the new EHR system. The new item had a loading of 0.740 . Third, we included the fourth item (OGS4) to capture healthcare providers' opinions on the levels of assistance provided by the hospital. The new item had a loading of 0.833 . Fourth, because our study aims to capture social influence sourcing from all possible employees at the hospital, it was necessary to include item SOI4, which captures social influence of superiors on the healthcare providers. This new item had a loading of 0.846 . Finally, we added a fourth item, PVL4, which captured healthcare providers' perceptions of value after considering the limitations of Hakeem.

\subsubsection{The Main Study}

After refining the survey items based on the pilot data's psychometric properties, we collected data for the main study from the entire hospital, but employees who completed the first survey (i.e., the pilot study) were specifically asked not to fill in the survey for the second time. We collected a total of 226 responses. Descriptive statistics are reported in Table 1.

\begin{tabular}{|c|c|cc|}
\hline \multicolumn{3}{|c|}{ Table 1. Descriptive Statistics of Respondents } \\
\hline \multicolumn{3}{|c|}{ Demographic Variables } & \multicolumn{2}{|c|}{ Data } \\
\hline Gender & Male & 133 & $(58.80 \%)$ \\
\cline { 2 - 4 } & Female & 93 & $(41.20 \%)$ \\
\hline Age & $<30$ & 56 & $(24.80 \%)$ \\
(Mean $=$ & $31-40$ & 87 & $(38.50 \%)$ \\
\cline { 2 - 4 } 33.02, & $41-50$ & 61 & $(27.00 \%)$ \\
\cline { 2 - 4 } S.D.= & $51-60$ & 22 & $(9.70 \%)$ \\
\cline { 2 - 4 } $\mathbf{5 . 1 9 )}$ & $>60$ & 0 & $(0.00 \%)$ \\
\hline Position & Physician & 57 & $(25.20 \%)$ \\
\cline { 2 - 4 } & Nurse & 70 & $(31.00 \%)$ \\
\cline { 2 - 4 } & Radiologist & 23 & $(10.20 \%)$ \\
\cline { 2 - 4 } & Lab Specialist & 32 & $(14.20 \%)$ \\
\cline { 2 - 4 } & Pharmacist & 15 & $(6.60 \%)$ \\
\cline { 2 - 4 } & Admin Staff & 20 & $(8.80 \%)$ \\
\cline { 2 - 4 } & Medical Student & 0 & $(0.00 \%)$ \\
\hline Total & & $\mathbf{2 2 6}$ & $(\mathbf{1 0 0} \%)$ \\
\hline
\end{tabular}

\subsection{Instrument Validation}

After the main data were collected, we tested the validity and reliability of the instrument using the Composite Reliability (CR), the Average Variance Extracted (AVE), Maximum Shared Variance (MSV), and Average Shared Variance (ASV) (Malhotra et al., 2006). All CR values were larger than 0.7 and AVE values larger than 0.5 . Additionally, we had MSV < AVE and ASV < AVE. This confirms the reliability of the instrument as well as its Convergent Validity and Discriminant Validity.

We also conducted CFA analysis again and all items had a significant loading greater than 0.7. All constructs had Cronbach's $\alpha$ values exceeding 0.8 . The CFA analysis provided strong support for our measurement model, which suggested that the items under each of the constructs were adequately measuring the constructs. Table A2 in the appendix lists the items' loadings and the model fit statistics for the CFA.

Further, we checked for nonresponse bias by testing the difference in means between two random pools of participants and found no significant difference between the two respondent groups based on the sample attributes (gender, age, and position).

\section{Results}

\subsection{Testing the Original Model}

The original research model (URM) was tested by applying Structural Equation Modeling (SEM). We applied the maximum likelihood estimator with robust standard errors (MLR). Figure 2 depicts the findings of testing the URM in this current study. None of the control variables had significant effect on resistance. Perceived value and switching costs' effects on user resistance explained $48.6 \%$ of its variance. Switching benefits explained $75.1 \%$ of the variance in perceived value. Social influence explained $19.2 \%$ of the variance in 
switching benefits. Social influence, organizational support, and self-efficacy for change's effects on switching costs explained $9.2 \%$ of its variance.

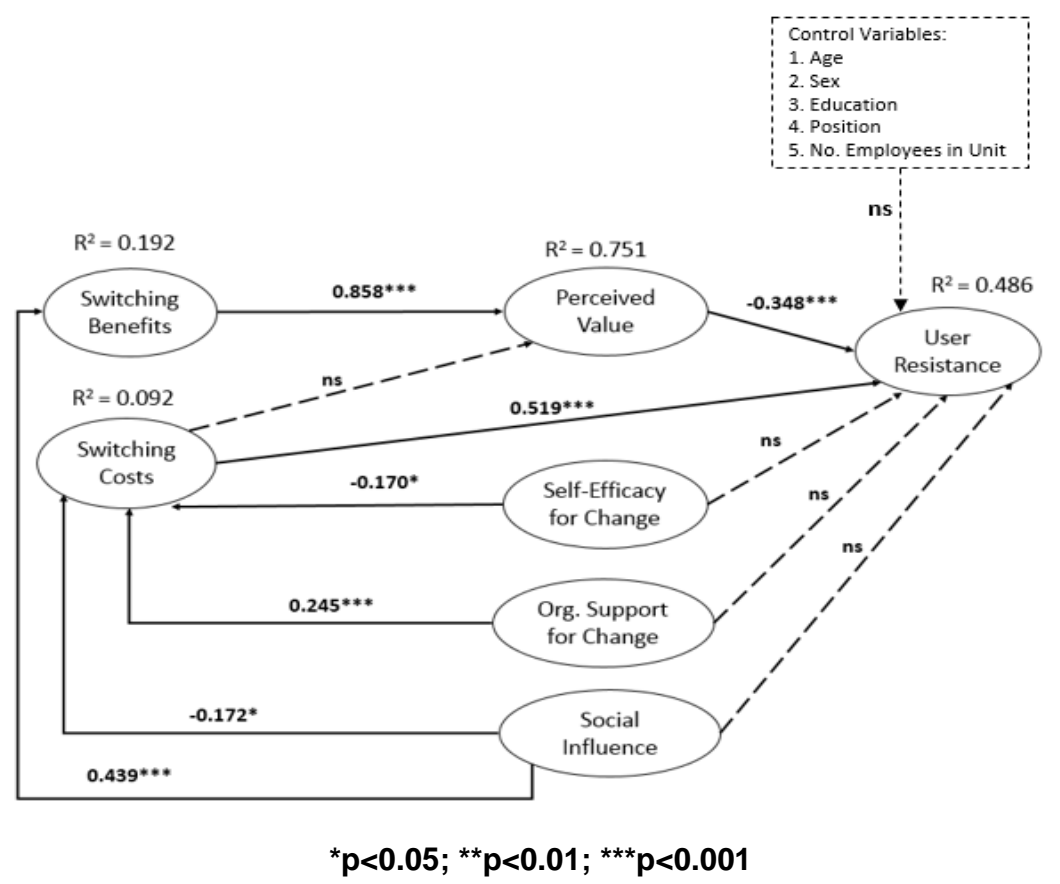

Figure 2. Results of testing URM in the new Context

Our findings show mixed results when compared to the URM findings. Table 2 represents a comparison between testing the hypotheses in both studies. We can see that there are discrepancies in the findings of $\mathrm{H} 2, \mathrm{H} 4$, and $\mathrm{H} 10$ from both studies.

\begin{tabular}{|c|c|c|c|}
\hline Hypothesis & $\begin{array}{l}\text { Hypothesized } \\
\text { Relationships }\end{array}$ & $\begin{array}{c}\text { URM } \\
\text { Hypothesis Support }\end{array}$ & $\begin{array}{c}\text { Current Study } \\
\text { Hypothesis Support }\end{array}$ \\
\hline $\mathrm{H} 1$ & SWB - PVL & Supported & Supported \\
\hline $\mathrm{H} 2$ & SWC - PVL & Supported & Not Supported \\
\hline $\mathrm{H} 3$ & SFC - SWC & Supported & Supported \\
\hline $\mathrm{H} 4$ & OGS - SWC & Not Supported & Supported (Positive Effect) \\
\hline $\mathrm{H} 5$ & SOI-SWC & Supported & Supported \\
\hline $\mathrm{H} 6$ & SOI-SWB & Supported & Supported \\
\hline $\mathrm{H} 7$ & SWC - RES & Supported & Supported \\
\hline $\mathrm{H} 8$ & $P V L$ - RES & Supported & Supported \\
\hline $\mathrm{H} 9$ & SFC - RES & Not Supported & Not Supported \\
\hline $\mathrm{H} 10$ & OGS - RES & Supported & Not Supported \\
\hline $\mathrm{H} 11$ & SOI - RES & Not Supported & Not Supported \\
\hline \multicolumn{4}{|c|}{$\begin{array}{l}\text { SWB }=\text { Switching Benefits } \\
\text { SWC = Switching Costs } \\
\text { PVL = Perceived Value } \\
\text { SFC = Self-efficacy } \\
\text { OGS = Organizational Support } \\
\text { SOI = Social Influence } \\
\text { RES = Resistance. }\end{array}$} \\
\hline
\end{tabular}


Because the URM is not saturated (i.e., not all possible regression paths were included) we evaluated the model fit indicators. The model fit statistics suggested that the current model does not have a good fit. This indicates that the URM in the healthcare context may need further investigation.

Following Bollen's (1998) suggestions on evaluating Chi-Square (X2), we calculated the Normed X2 $(\mathrm{NC}=3.91)$. It is suggested that $\mathrm{NC}$ value between 2.0 and 6.0 indicates reasonable fit. However, we noticed that $\mathrm{CFI}=0.882$, which indicates an ill fit in the model. The rule of thumb for the CFI and other incremental indices is that values greater than roughly .90 may indicate reasonably good fit of the researcher's model (Hu and Beltler, 1999). Additionally, the Root Mean Square Error of Approximation (RMSEA) is 0.114. According to the rules of thumb by Browne et al (1993), RMSEA values between 0.05 and 0.08 suggest reasonable error of approximation and values greater than 0.1 suggest poor fit.

\subsection{Improving Model Fit}

We conducted a Modification Indices Test (MIT) using MPlus to find alternative models that have adequate grounding in theory and have improved fit. The MIT found the best model fit achieved by adding the following three paths: (1) direct effect of switching benefits on resistance, (2) self-efficacy on switching benefits, and (3) organizational support on switching benefits. Additionally, the model dropped all three direct effects of social influence, organizational support, and self-efficacy for change on user resistance.

The new suggested model is depicted in Figure 3 and the new model indices, which are significantly improved, are presented in Table 3.

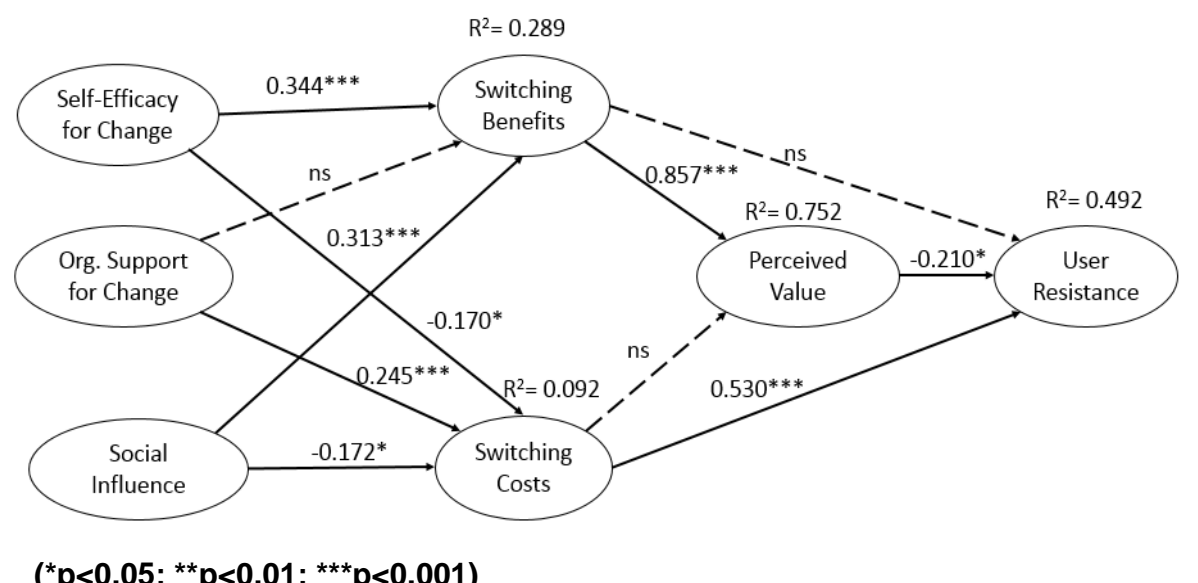

$\left({ }^{*} \mathrm{p}<0.05 ;{ }^{* *} \mathrm{p}<0.01 ;{ }^{* * *} \mathrm{p}<0.001\right)$

Figure 3. Suggested Model Results

\begin{tabular}{|l|l|}
\hline \multicolumn{2}{|l|}{ Table 3. Suggested Model Fit Indices } \\
\hline Indicator & Value \\
\hline X2 & 52.330 \\
\hline df & 22 \\
\hline P-Value & 0.0003 \\
\hline Calculated NC & 2.378 \\
\hline CFI & 0.944 \\
\hline RMSEA & 0.078 \\
\hline 90 Cl & $0.051-0.106$ \\
\hline SRMR & 0.046 \\
\hline
\end{tabular}

The suggested model had no notable change in the amount of variance explained, except for switching benefits (28.9\%), which increased from 19.2\%. However, the suggested model had a better fit. NC was at 2.3; CFI increased to 0.944 , which is in the recommended range (>0.9); and RMSEA became lower (0.078), also in the reasonable range $(0.05-0.10)$. The only new significant path is the positive effect of self-efficacy for change on switching benefits. The more healthcare providers feel confident in their skills and abilities to 
master the new way of working with the EHR system, the more they will perceive the change as beneficial. This falls along the URM theory, which hypothesized the negative effect self-efficacy for change has on switching costs.

\section{Discussion}

Testing the original model in the context of this study resulted in a number of interesting findings. First, switching costs in this study had a direct effect on resistance but the indirect effect via perceived value was not statistically significant, whereas Kim and Kankanhalli's initial test of the URM had both effects significant. In our study, healthcare providers perceived switching costs of the EHR as a main contributor to their resistance; however, it had no effect on their perception of the EHR value. This indicates that unlike other technologies, the costs associated with EHR are enough to trigger resistance while keeping the perceptions of its value intact. This finding may be different if loss aversion items are included in the perceived value scale items. Loss aversion suggests that when evaluating a situation, people will value losses more than gains. This is especially true in the healthcare context, where losses could be directly aimed toward the health of patients. When healthcare providers are delivering care with a suggested success rate of the treatment, they are expected to value the failure of the procedure heavily and direct their focus on avoiding it. We believe that, as a matter of automatic behavior, healthcare providers will weigh costs much more than they weigh benefits in any given evaluation case. Therefore, the loss aversion concept can be used to help explain this finding. Additionally, our finding could be explained by the concept of perceived consequences, which refers to the cognitive evaluation of the probable consequences of the behavior (Gagnon et al., 2010). Najaftorkaman et al (2015) suggested that healthcare providers' perceived consequences of using EHR systems have a significant impact on their adoption behaviors of the EHR. Thus, when healthcare providers know about the various costs and consequences of using EHR systems, they begin to resist EHR systems. This perception of consequences is found to be stronger than, and independent from, their beliefs of the value associated with the EHR system.

Second, while switching costs in our study mediated the effect of other factors on resistance (i.e., selfefficacy for change and social influence); we find the contradicting effect of organizational support for change on switching costs. Organizational support in our study had a positive effect on switching costs, which in turn has a positive direct effect on resistance. This means the more healthcare providers perceive the hospital as being supportive to the change to the EHR, the more they perceive the change as being burdensome in terms of their transition, uncertainty, and sunk costs. This is opposite to what the URM theory suggested (i.e., the negative effects of organizational support for change on switching cost). This relationship was not significant in the original URM model tested in the context of IT service organization, where perceptions about the organizational support and perceived cost were captured before the implementation of the technology. However, in this study we captured these perceptions after the implementation of the EHR was complete and the transition was in progress. So, healthcare providers were able to provide a clear opinion of the support provided by their hospital and how this support was perceived by them in terms of its effect on switching costs. Additionally, healthcare organizations are aware of a number of compelling issues surrounding EHR systems that keep them motivated to provide support to their EHR users. First, EHR systems consist of complex software and hardware that requires certain skills in order to be applied in the workplace (Boonstra and Broekhuis, 2010). Second, one of the most important barriers to EMR adoption is a lack of computer proficiency (Najaftorkaman et al., 2015). Third, some healthcare providers are still interested in documenting their work using PBRS instead of using EHR systems. If these healthcare providers cannot embrace EHR in their workplaces, the resistance to EHR systems can rapidly increase in healthcare organizations (Pinaire, 2009). Therefore, healthcare organizations tend to offer training sessions to their healthcare providers who are expected to interact with the EHR system, as well as provide technical support to users as needed. However, healthcare providers at the hospital may be perceiving increased support from the hospital as an indication that the transition is difficult and requires special support, and this may result in an increase in the perceived transition costs. Furthermore, hospital support may be in the form of training sessions, which means there will be new skills to be learned and new knowledge to be mastered, and this may increase levels of sunk costs. Moreover, hospital support for the change may be unclear on how this would affect healthcare providers' productivities and performances, which may lead to an increase in their uncertainty costs. Healthcare providers' focus is mainly directed toward their patients. Thus, they have little interest in changing the way they perform their tasks as long as there is no resulting direct effect on their patients. So, when the hospital provides support (e.g., active training sessions) to their employees, healthcare providers may perceive this as an unnecessary overhead that requires spending more time in classrooms with computers and less time 
dedicated toward improving the health of their patients. Thus, the more organizational support was perceived, the higher switching costs were reported. This positive effect of hospital support on switching costs is an interesting finding, especially since switching costs is a composite construct and the effect may be directed to one or more of the types of costs. We encourage future research to further explore this finding.

Third, unlike the URM findings, this study shows that organizational support has no direct effects on resistance. This is related to our previous argument on hospital support. Healthcare organizations need to be mindful of users' needs and must choose the proper method of support carefully. Our findings indicate that the type of support chosen by the hospital is increasing healthcare providers' perceptions of EHR's costs and is not impacting their resistance. We encourage future research to further explore what type of support was used by the hospital in this study and why healthcare providers responded negatively to hospital support. Additionally, future research may aim to provide a comparative analysis between different types of support provided by healthcare organizations and how healthcare providers respond to each.

Just like the URM, H9 is not supported in this study. Self-efficacy for change has no direct impact on resistance. Rather, there is an indirect effect mediated through switching costs. This result indicates that self-efficacy for change reduces healthcare providers' resistance to change indirectly through reducing switching costs. This result extends previous findings on technologies, not limited to HIT, that self-efficacy increases ease of use (Venkatesh, 2000) since switching cost includes both ease of use and "ease of learning" the new technology (Kim and Kankanhalli, 2009). One plausible reason for the insignificant direct effect of self-efficacy of change on resistance is that we have captured individuals' beliefs in their ability to change to the new way of working with the EHR rather than their beliefs about their ability to directly use the EHR. Healthcare providers may be confident in their ability to adapt to the transition process of the hospitals in terms of redirecting the use of resources, work processes, budget allocations, or any other modes of operation that will reshape the hospital, but not confident in their ability to use the new technology on their own. It has been shown in the literature that computer literacy has a negative impact on EHR resistance and healthcare providers with fewer computer skills are less likely to adopt the systems (Stream, 2009; Terry et al., 2009). Using EHR systems could be a completely new experience for some healthcare providers in their workplace. Some EHR users are not confident about their ability to use it (Simon et al., 2007; Terry et al., 2009). Therefore, we call on future research to investigate the impact of self-efficacy of using the EHR technology on resistance.

Also, just like the URM, $\mathrm{H} 11$ is not supported in this study. Social influence has no direct effect on resistance. We included items to capture influence from superiors at the hospital. Thus, different opinions may have been perceived from different sources. For example, including superiors' influence with other type of influences (i.e., from colleagues and peers) may result in mixed opinions that in turn may have contributed to the result of having no direct relation between social influence and resistance.

The suggested model, depicted in figure 3 , had a better model fit with accepted model fit indices. Adding the direct effect of switching benefits on resistance into the model aligns with the URM theory. The URM was built on the basis of net benefits and net equity concepts. Both of these concepts suggest that the evaluation of the change is mainly based on the perceived benefits of the switch against the perceived costs of the switch. Thus, just as it is hypothesized that switching costs will have a positive direct effect on resistance, switching benefits is hypothesized to have a negative direct effect on resistance. This is very relevant in the healthcare context, where healthcare providers tend to enjoy more freedom when it comes to choosing the type of HIT that they feel comfortable using. If healthcare providers feel that the switch to the new EHR system is beneficial, they will be less inclined to resist it.

Similarly, adding the path between self-efficacy and switching benefits aligns with the theoretical approach of the URM. Higher self-efficacy will increase levels of confidence potential users have regarding the switch and will therefore increase the perceived benefits of the switch. Being able to handle the change with no self-efficacy problems indicates that the potential user is capable of working in the new environment with no significant challenges. This makes it easier for him/her to realize the benefits associated with the switch. On the other hand, when lower levels of self-efficacy are present, the potential user will be more focused toward overcoming the associated problems related to his/her low self-efficacy regarding the change, and this will result in fewer realizations of the benefits associated with the switch. This is especially true within the healthcare context. Healthcare providers can appreciate the benefits of the switch to the new EHR only if they have the sufficient knowledge and skills to interact with the EHR without having to spend the time and effort required to master the change. 
The third path added is between organizational support and switching benefits. This also conforms to the theoretical lens of the URM. When organizations provide adequate support to their employees about the change, employees better realize the benefits associated with the switch. Organizational support mechanisms such as training and providing resources could affect individuals' reactions toward change to the new EHR system (Hirschheim and Newman, 1988). Additionally, these mechanisms would maximize the perceived benefits of adapting to the new EHR system (Lewis et al., 2003). The more support offered by the hospital to healthcare providers, the more discussions and presentations about the change would be available, and hence, healthcare providers become more aware of benefits associated with the switch.

Findings of testing the URM in the context of this study were different from those of the original study. These results can be partially explained by the difference in context between studies. In this study, we test resistance towards the new mandated system after its implementation, while the original study tested the URM with a voluntary system at the pre-implementation stage. Interestingly, even when there are no other alternatives, since the PBRS is no longer available, and after the EHR implementation, users still feel negatively towards the system. Additionally, in the original study, employees were using an electronic system to perform the tasks prior to the implementation of the new system, while in this study employs used a paper-based system before the switch to the fully-electronic system.

\section{Limitations}

This study has its limitations. In order to fully understand the positive effect between organizational support and switching costs, further investigations are required. It is interesting to study how different types of support provided by healthcare organizations may influence cost perceptions of EHR systems differently. Additionally, although measuring loss aversion within the perceived value construct may give new insights about the scale, but we did not use it in this study. Future studies could attempt to empirically validate these items.

\section{Contributions}

\subsection{Contributions to Research}

Our study makes key contributions to IS research. First, by providing a conceptual replication of the comprehensive theoretically grounded model of URM, we are addressing the need for more replication studies in the IS field (Dennis and Valacich, 2014). Second, this replication study helps in strengthening theory on technology resistance by examining the original research model in a different environment such as the healthcare context in a developing country (Dennis and Valacich, 2014; Tsang and Kwan, 1999; Asamoah et al., 2015). Replicating the URM in a new context shows that this model, if appropriately modified, could be adapted to explain resistance to mandatory use of newly implemented IS in different contexts. This study suggests that the constructs of the URM are relevant in the new environment while being aware of the healthcare-specific contextual considerations.

Third, this study's findings advance the theoretical understanding of the factors that shape resistance to EHR. Much of what exists in the literature about EHR is directed at explaining its adoption. To our knowledge this is the first study that comprehensively models the antecedents to predict and explain resistance to EHR. By first testing the existing URM and then adjusting it to better fit the EHR context, we offer a robust model that can be used as a foundation to build and develop future models to better understand the EHR resistance phenomenon. The interesting findings, such as counterintuitive effects of organizational support on switching cost, effects of self-efficacy and social influences on cost and benefit of switching to newlyimplemented EHR, should motivate future work to uncover additional costs and benefits surrounding this phenomenon. In addition, future work could also examine how these perceived costs and benefits vary across different demographic groups. For instance, literature suggests that individual differences play a role in resistance within the healthcare context (Samhan and Joshi, 2015). However, our findings reveal that demographic indicators such as age, gender, position at the hospital, or levels of education are not significant, at least for our sample, in explaining EHR resistance. Future research needs to further examine the role individual differences play in this phenomenon.

Finally, this study makes a methodological contribution by providing a validated instrument that can be used in the healthcare context. Although the scales used in this instrument were adapted from the literature, the items were revised iteratively through multiple rounds of literature-driven discussion among the authors, 
pre-pilot content validation from potential participants, and an extensive pilot study where the psychometric properties of all the scales were rigorously evaluated.

\subsection{Contributions to Practice}

Our study provides a number of implications to practice. First, we provide possible solutions to hospitals and other health organizations when trying to reduce resistance toward the change to new EHR systems. Switching cost has a direct effect on resistance. Thus, reducing it is critical when aiming to eliminate resistance. This could be achieved by enhancing positive opinions about the change both from colleagues and superiors. Also, it is very crucial to understand what type of support is more suitable for the healthcare providers. Our findings show that hospital support has a positive effect on switching costs. This may be due to inappropriate delivery of the support (e.g., long training sessions for healthcare providers after hours). Additionally, investing in healthcare providers' development to increase their self-efficacy would have direct impacts on their perception of the switch in terms of its costs vs. its benefits. Also, it is important to emphasize the advantages of the EHR system and to explain the core benefits of the switch at early stages before the implementation of the EHR system. This would help in increasing switching benefits and perceived value, which in turn would reduce resistance. Second, because this study is conducted in a developing country, which is still in the first stages of digitizing healthcare organizations, it becomes very important to understand what predicts resistance to change to new EHR systems and what new users consider as benefits or costs to the switch. Answers to these questions would help system developers and system designers build improved EHR systems that overcome sources of costs. Third, understanding EHR resistance would help healthcare providers get the appropriate support to reduce resistance motivations. Governments in many countries have heavily invested in the transition to EHR systems (Khalifa, 2013). Thus, being able to explain causes of HIT resistance would help in finding solutions to make these systems more adopted and with higher success rates. Findings would help practitioners better understand resistance in the context in which it was tested, and that would serve as the first step toward solving problems associated with resistance.

\section{References}

Angst, C. M., and Agarwal, R. (2009). Adoption of electronic health records in the presence of privacy concerns: The elaboration likelihood model and individual persuasion. MIS Quarterly, 33(2), 339-370.

Asamoah, D., Andoh-Baidoo, F. K., and Agyei-Owusu, B. (2015). Impact of ERP implementation on business process outcomes: A replication of a United States study in a Sub-Saharan African Nation. AIS Transactions on Replication Research, 1(1), 4.

Akhu-Zaheya, L., Al-Maaitah, R., \& Bany Hani, S. (2018). Quality of nursing documentation: Paper-based health records versus electronic-based health records. Journal of Clinical Nursing, 27(3-4), e578e589.

Blumenthal, D., and Tavenner, M. (2010). The "meaningful use" regulation for electronic health records. New England Journal of Medicine, 363(6), 501-504.

Bollen KA. (1998). Structural equation models. In Encyclopedia of Biostatistics, ed. P Armitage, T Colton, pp. 4363-72. Sussex, UK: Wiley

Boonstra, A., and Broekhuis, M. (2010). Barriers to the acceptance of electronic medical records by physicians from systematic review to taxonomy and interventions. BMC Health Services Research, 10(1), 1.

Browne, Michael W., and Robert Cudeck. (1993). Alternative ways of assessing model fit. Sage Focus Editions, 154, 136-136.

Buchbinder, S. B., and Shanks, N. H. (2016). Introduction to health care management. Burlington, MA: Jones and Bartlett Publishers.

Cialdini, R. B., and Goldstein, N. J. (2004). Social influence: Compliance and conformity. Annual Review of Psychology, 55, 591-621.

Cotea, C. (2010). Electronic health record adoption: Perceived barriers and facilitators. Centre for Military and Veterans' Health: The University of Queensland. 
Dennis, A. R., and Valacich, J. S. (2014). A Replication Manifesto. AlS Transactions on Replication Research, 1, 1-5.

Electronic Health Solutions (EHS). http://www.ehs.com.jo/en.

Gagnon, M.-P., Ouimet, M., Godin, G., Rousseau, M., Labrecque, M., Leduc, Y., et al. (2010). Study protocol multi-level analysis of electronic health record adoption by health care professionals: A study protocol. Implementation Science, 30(5), 1-10.

Halamka, John. (2011). Healthcare is different. http://geekdoctor.blogspot.com/2011/08/healthcare-isdifferent.html.

Hsieh, P. J. 2015. Healthcare Professionals' Use of Health Clouds: Integrating Technology Acceptance and Status Quo Bias Perspectives, International Journal of Medical Informatics (84:7), pp. 512-523.

Hsieh, P. J., and Lin, W. S. 2018. Explaining Resistance to System Usage in the PharmaCloud: A View of the Dual-Factor Model, Information \& Management (55:1), pp. 51-63.

Hillestad, R., Bigelow, J., Bower, A., Girosi, F., Meili, R., Scoville, R., and Taylor, R. (2005). Can electronic medical record systems transform health care? Potential health benefits, savings, and costs. Health Affairs, 24(5), 1103-1117.

Hu, L.T. and Bentler, P.M. (1999). Cutoff criteria for fit indexes in covariance structure analysis: Conventional criteria versus new alternatives, Structural Equation Modeling, 6(1), 1-55.

IBM Corp. (2013). IBM SPSS Statistics for Windows, Version 22.0. Armonk, NY: IBM Corp.

Khalifa, M. (2013). Barriers to health information systems and electronic medical records implementation. A field study of Saudi Arabian hospitals. Procedia Computer Science, 21, 335-342.

Kim, H.-W., and Kankanhalli, A. (2009). Investigating user resistance to information systems implementation: a status quo bias perspective. MIS Quarterly 33(3).

Kruse, C. S., Kristof, C., Jones, B., Mitchell, E., \& Martinez, A. (2016). Barriers to electronic health record adoption: a systematic literature review. Journal of Medical Systems, 40(12), 252.

Lapointe, L., and Rivard, S. (2005). A multiple model of resistance to information technology implementation. MIS Quarterly, (29)3, 461-491.

Lewis, W., Agarwal, R., and Sambamurthy, V. (2003). Sources of influence on beliefs about information technology use: An empirical study of knowledge workers." MIS Quarterly, (27)4, 657-678.

Malhotra, N. K., Kim, S. S., \& Patil, A. (2006). Common method variance in IS research: A comparison of alternative approaches and a reanalysis of past research. Management science, 52(12), 1865-1883.

MPLUS (Version 6.11). [Computer Software]. Los Angeles, CA: Muthén and Muthén.

Najaftorkaman, M., Ghapanchi, A. H., Talaei-Khoei, A., and Ray, P. (2015). A taxonomy of antecedents to user adoption of health information systems: A synthesis of thirty years of research. Journal of the Association for Information Science and Technology, 66(3), 576-598.

Ngafeeson, M. N., and Midha, V. (2014). An exploratory study of user resistance in healthcare IT. International Journal of Electronic Finance, 8(1), 74-94.

Nov, O., and Schecter, W. (2012). Dispositional resistance to change and hospital physicians' use of electronic medical records: A multidimensional perspective. Journal of the American Society for Information Science and Technology, 63(4), 648-656.

Olaniran, B. A. (2015). Contextual factors and challenges to e-health literacy. Knowledge Management and E-Learning: An International Journal (KMandEL),7(4), 616-628.

Reardon, J. L., and Davidson, E. (2007). An organizational learning perspective on the assimilation of electronic medical records among small physician practices. European Journal of Information Systems, 16(6), 681-694.

Samhan, B., and Joshi, K. D. (2015, January). Resistance of Healthcare Information Technologies; Literature Review, Analysis, and Gaps. 2015 48th Hawaii International Conference. IEEE. 
Sassen, E.J. (2009). Love, hate, or indifference: How nurses really feel about the electronic health record system. Computers, Informatics, Nursing, 27(5), 281-287.

Sheikh, A., Cornford, T., Barber, N., Avery, A., Takian, A., Lichtner, V. and Morrison, Z. (2011). Implementation and adoption of nationwide electronic health records in secondary care in England: final qualitative results from prospective national evaluation in "early adopter" hospitals. $B M J, 343$, d6054.

Simon, S.R., Kaushal, R., Cleary, P.D., Jenter, C.A., Volk, L.A., Poon, E.G., et al. (2007). Correlates of electronic health record adoption in office practices: A statewide survey. Journal of the American Medical Informatics Association, 14(1), 110-117.

Stone, C. P. (2014). A glimpse at EHR implementation around the world: The lessons the US can learn. The Health Institute for E-Health Policy. http://www.ehealthpolicy.org/docs/A Glimpse at EHR Implementation Around the World1 ChrisStone.pdf

Stream, G.R. (2009). Trends in adoption of electronic health records by family physicians in Washington State. Informatics in Primary Care, 17(3), 145-152.

Terry, A.L., Giles, G., Brown, J.B., Thind, A., and Stewart, M. (2009). Adoption of electronic medical records in family practice: The providers' perspective. Family Medicine, 41(7), 508.

Terry, K. (15 November 2012). EHR adoption: U.S. remains the slow poke. Information Week. Retrieved from http://www.informationweek.com/healthcare/electronic-healthrecords/ehr-adoption-us-remainsthe-slow-poke/d/d-id/1107410?

Tsang, E. W., \& Kwan, K.-M. (1999). Replication and theory development in organizational science: A critical realist perspective. Academy of Management Review, 24(4), 759-780.

Venkatesh, V. (2000). Determinants of perceived ease of use: Integrating control, intrinsic motivation, and emotion into the technology acceptance model. Information Systems Research, 11(4), 342-365.

Vishwanath, A., and Scamurra, S. D. (2007). Barriers to the adoption of electronic health records: using concept mapping to develop a comprehensive empirical model. Health Informatics Journal, 13(2), 119-134.

Weeger, A., Gewald, H., and Vriesman, L. J. (2011). Do risk perceptions influence physician's resistance to use Electronic Medical Records? An exploratory research in German hospitals. In Proceedings of the American Conference on Information Systems (AMCIS), Association for Information Systems (AIS), Detroit, MI.

Xue, Y., Liang, H., Mbarika, V., Hauser, R., and Schwager, P. (2014). Understanding healthcare professionals' resistance of telemedicine: An empirical study in Ethiopia. In the proceedings of PACIS, Chengdu, China. p.225. 


\section{Appendix A: Measurement Instrument and Items Loadings}

\begin{tabular}{|c|c|c|}
\hline \multicolumn{3}{|r|}{ Table A1. Measurement Instrument } \\
\hline Construct & Item & Wording \\
\hline \multirow{4}{*}{ Switching Benefits } & SWB1 & $\begin{array}{l}\text { Changing to the new way of working with Hakeem enhances } \\
\text { my effectiveness on the job more than working using the } \\
\text { previous paper-based system. }\end{array}$ \\
\hline & SWB2 & $\begin{array}{l}\text { Changing to the new way of working with Hakeem enables me } \\
\text { to accomplish relevant tasks more quickly than working using } \\
\text { the previous paper-based system. }\end{array}$ \\
\hline & SWB3 & $\begin{array}{l}\text { Changing to the new way of working with Hakeem increases } \\
\text { my productivity more than working with the previous paper- } \\
\text { based system. }\end{array}$ \\
\hline & SWB4 & $\begin{array}{l}\text { Changing to the new way of working with Hakeem improves } \\
\text { the quality of the work I do more than working with the previous } \\
\text { paper-based system. }\end{array}$ \\
\hline \multirow{4}{*}{ Perceived Value } & PVL1 & $\begin{array}{l}\text { Considering the time and effort that I have to spend, the } \\
\text { change to the new way of working with Hakeem is worthwhile. }\end{array}$ \\
\hline & PVL2 & $\begin{array}{l}\text { Considering the loss that I incur, the change to the new way of } \\
\text { working with Hakeem is of good value. }\end{array}$ \\
\hline & PVL3 & $\begin{array}{l}\text { Considering the hassle that I have to experience, the change } \\
\text { to the new way of working with Hakeem is beneficial to me. }\end{array}$ \\
\hline & $\mathrm{PVL}^{*}$ & $\begin{array}{l}\text { Considering Hakeem's limitations, the change to the new way } \\
\text { of working with Hakeem is advantageous. }\end{array}$ \\
\hline \multirow{4}{*}{ Switching Costs } & SWC1 & $\begin{array}{l}\text { I already have put a lot of time and effort into mastering the } \\
\text { previous paper-based system. }\end{array}$ \\
\hline & SWC2 & $\begin{array}{l}\text { It took a lot of time and effort to switch to the new way of } \\
\text { working with Hakeem. }\end{array}$ \\
\hline & SWC3 & $\begin{array}{l}\text { Switching to the new way of working with Hakeem resulted in } \\
\text { unexpected hassles. }\end{array}$ \\
\hline & SWC4 & $\begin{array}{l}\text { I lost a lot in my work after switching to the new way of working } \\
\text { with Hakeem. }\end{array}$ \\
\hline \multirow{4}{*}{ Social Influence ${ }^{* *}$} & SOl1 & $\begin{array}{l}\text { Most of my colleagues think the change to the new way of } \\
\text { working with Hakeem is a good idea. }\end{array}$ \\
\hline & SOI2 & $\begin{array}{l}\text { My peers are supportive of the change to the new way of } \\
\text { working with Hakeem. }\end{array}$ \\
\hline & $\mathrm{SOI} 3$ & $\begin{array}{l}\text { Most people whom I deal with in my job encourage my change } \\
\text { to the new way of working with Hakeem. }\end{array}$ \\
\hline & $\mathrm{SOI}^{*}$ & $\begin{array}{l}\text { Most of my superiors think that the change to the new way of } \\
\text { working with Hakeem is a good idea. }\end{array}$ \\
\hline \multirow{4}{*}{$\begin{array}{l}\text { Self-Efficacy for } \\
\text { Change }\end{array}$} & SFC1 & $\begin{array}{l}\text { I was able to change to the new way of working with Hakeem } \\
\text { easily based on my own knowledge, skills and abilities. }\end{array}$ \\
\hline & SFC2 & $\begin{array}{l}\text { I was able to change to the new way of working with Hakeem } \\
\text { without the help of others. }\end{array}$ \\
\hline & SFC3 & $\begin{array}{l}\text { I was able to change to the new way of working with Hakeem } \\
\text { reasonably well on my own. }\end{array}$ \\
\hline & SFC4* & $\begin{array}{l}\text { I had confidence in my ability to change to the new way of } \\
\text { working with Hakeem without any difficulties. }\end{array}$ \\
\hline \multirow{3}{*}{$\begin{array}{l}\text { Organizational } \\
\text { Support for } \\
\text { Change }\end{array}$} & OGS1 & $\begin{array}{l}\text { My hospital provided me with guidance on how to change to } \\
\text { the new way of working with Hakeem. }\end{array}$ \\
\hline & OGS2 & $\begin{array}{l}\text { The management at my hospital provided the necessary help } \\
\text { and resources to enable me to change to the new way of } \\
\text { working with Hakeem. }\end{array}$ \\
\hline & OGS3 & $\begin{array}{l}\text { I was given the necessary support and assistance by my } \\
\text { hospital to change to the new way of working with Hakeem. }\end{array}$ \\
\hline
\end{tabular}




\begin{tabular}{|l|l|l|}
\hline \multirow{3}{*}{ OGS4* } & $\begin{array}{l}\text { The assistance provided by my hospital made the change to } \\
\text { the new way of working with Hakeem easier. }\end{array}$ \\
\hline \multirow{3}{*}{ User Resistance } & RES1 & $\begin{array}{l}\text { I would rather not comply with the change to the new way of } \\
\text { working with Hakeem. }\end{array}$ \\
\cline { 2 - 3 } & RES2 & $\begin{array}{l}\text { I would rather not cooperate with the change to the new way } \\
\text { of working with Hakeem. }\end{array}$ \\
\cline { 2 - 3 } & RES3 & I oppose the change to the new way of working with Hakeem. \\
\cline { 2 - 3 } & RES4 & $\begin{array}{l}\text { I do not agree with the change to the new way of working with } \\
\text { Hakeem. }\end{array}$ \\
\hline
\end{tabular}

*New item developed for this study

** This study uses the construct Social Influence to capture items from the College Opinion construct in the URM while also including item (SOI4) to capture superiors' influence.

\begin{tabular}{|c|c|c|c|c|c|c|}
\hline Construct & Item & $\begin{array}{l}\text { Std. } \\
\text { Loading }\end{array}$ & Mean & STD & Cronbach's $\alpha$ & $\begin{array}{ll}\text { CFA Model Fit } \\
\text { Statistics }\end{array}$ \\
\hline \multirow{4}{*}{ SWB } & SWB1 & 0.935 & \multirow{4}{*}{3.341} & \multirow{4}{*}{1.201} & \multirow{4}{*}{0.976} & \multirow{4}{*}{$\begin{array}{l}\text { X2: } \\
\text { df: } 2 \\
\text { P < } 0.05 \\
\text { CFI: } 0.983 \\
\text { RMSEA: } 0.101 \\
\text { Cl: } 0.022-0.191 \\
\text { SRMR: } 0.007\end{array}$} \\
\hline & SWB2 & 0.946 & & & & \\
\hline & SWB3 & 0.987 & & & & \\
\hline & SWB4 & 0.947 & & & & \\
\hline \multirow{4}{*}{ SWC } & SWC1 & 0.702 & \multirow{4}{*}{3.301} & \multirow{4}{*}{0.868} & \multirow{4}{*}{0.896} & \multirow{4}{*}{$\begin{array}{l}\text { X2: } \\
\text { df: } 2 \\
\text { P < } 0.01 \\
\text { CFI: } 0.961 \\
\text { RMSEA: } 0.145 \\
\text { Cl: } 0.072-0.231 \\
\text { SRMR: } 0.029\end{array}$} \\
\hline & SWC2 & 0.859 & & & & \\
\hline & SWC3 & 0.848 & & & & \\
\hline & SWC4 & 0.898 & & & & \\
\hline \multirow{4}{*}{ PVL } & PVL1 & 0.953 & \multirow{4}{*}{3.239} & \multirow{4}{*}{1.090} & \multirow{4}{*}{0.981} & \multirow{4}{*}{$\begin{array}{l}\text { X2: } \\
\text { df: } 2 \\
\text { P < } 0.05 \\
\text { CFI: } 0.971 \\
\text { RMSEA: } 0.059 \\
\text { CI: } 0.000-0.120 \\
\text { SRMR: } 0.181\end{array}$} \\
\hline & PVL2 & 0.969 & & & & \\
\hline & PVL3 & 0.956 & & & & \\
\hline & PVL4 & 0.976 & & & & \\
\hline \multirow{4}{*}{ SFC } & SFC1 & 0.761 & \multirow{4}{*}{3.447} & \multirow{4}{*}{0.889} & \multirow{4}{*}{0.910} & \multirow{4}{*}{$\begin{array}{l}\text { X2: } 36.673 \\
\text { df: } 2 \\
\text { P }<0.001 \\
\text { CFI: } 0.904 \\
\text { RMSEA: } 0.227 \\
\text { CI: } 0.203-0.359 \\
\text { SRMR: } 0.048\end{array}$} \\
\hline & SFC2 & 0.888 & & & & \\
\hline & SFC3 & 0.977 & & & & \\
\hline & SFC4 & 0.740 & & & & \\
\hline \multirow{5}{*}{ SOI } & SOI1 & 0.925 & \multirow{4}{*}{3.642} & \multirow{4}{*}{0.848} & \multirow{4}{*}{0.945} & \multirow{4}{*}{$\begin{array}{l}\text { X2: } 15.969 \\
\text { df: } 2 \\
\text { P }<0.001 \\
\text { CFI: } 0.957 \\
\text { RMSEA: } 0.176 \\
\text { Cl: } 0.103-0.206 \\
\text { SRMR: } 0.023\end{array}$} \\
\hline & SOI2 & 0.927 & & & & \\
\hline & $\mathrm{SOl} 3$ & 0.902 & & & & \\
\hline & SOI4 & 0.846 & & & & \\
\hline & OGS1 & 0.851 & & & & X2: 9.820 \\
\hline
\end{tabular}




\begin{tabular}{|c|c|c|c|c|c|c|}
\hline \multirow{4}{*}{ OGS } & & & \multirow{4}{*}{3.602} & \multirow{4}{*}{0.755} & \multirow{4}{*}{0.943} & \multirow{4}{*}{$\begin{array}{l}\text { df: } 2 \\
P<0.05 \\
\text { CFI: } 1.00 \\
\text { RMSEA: } 0.000 \\
\text { Cl: } 0.000-0.107 \\
\text { SRMR: } 0.004\end{array}$} \\
\hline & OGS2 & 0.956 & & & & \\
\hline & OGS3 & 0.958 & & & & \\
\hline & OGS4 & 0.833 & & & & \\
\hline \multirow{4}{*}{ RES } & RES1 & 0.968 & \multirow{4}{*}{2.938} & \multirow{4}{*}{1.129} & \multirow{4}{*}{0.982} & \multirow{4}{*}{$\begin{array}{l}\text { X2: } 8.420 \\
\text { df: } 2 \\
\text { P < } 0.05 \\
\text { CFI: } 1.00 \\
\text { RMSEA: } 0.000 \\
\text { CI: } 0.000-0.102 \\
\text { SRMR: } 0.001\end{array}$} \\
\hline & RES2 & 0.992 & & & & \\
\hline & RES3 & 0.985 & & & & \\
\hline & RES4 & 0.919 & & & & \\
\hline
\end{tabular}




\section{About the Authors}

Bahae Samhan is a Business Information Systems Assistant Professor in the College of Business at Illinois State University. He earned his PhD in MIS from Washington State University in 2016. Beside his research on Health Information Technology, he is interested in Social Network Analysis and Replication Research. His work appeared in many specialized journals including the International Journal of Electronic Health, the Australasian Journal of Information Systems, and the International Journal of Healthcare Management.

KD Joshi is a Professor and Department Chair of Information Systems in the College of Business at the University of Nevada, Reno. She received her Master of Science in Engineering from the University of Michigan and received her Doctor of Philosophy in Business Administration (Decision Sciences and Information Systems) from the University of Kentucky. Dr. Joshi's research interests focus on IT Workforce Issues, Broadening Participation in STEM, Knowledge Management, Crowdsourcing, IT-Enabled Innovation, Value Sensitive Designs, and Health IT. Her published research is cited over 5,400 times (an hindex of 26) according to Google Scholar and her research has been featured in numerous media outlets such PBS NewsHour, Salon.com, Vancouver Business Journal, London School of Economic Business Review, Puget Sound Business Journal, \& Military.Com. She has been a Principal Investigator or CoPrincipal Investigator on grants totaling over \$5M from the National Science Foundation (NSF). Her research has appeared in journals such as MIS Quarterly, Information Systems Research, Journal of the AIS, Information Systems Journal, Decision Support Systems, IEEE Transactions of Engineering Management, and Communications of the ACM.

Copyright @ 2019 by the Association for Information Systems. Permission to make digital or hard copies of all or part of this work for personal or classroom use is granted without fee provided that copies are not made or distributed for profit or commercial advantage and that copies bear this notice and full citation on the first page. Copyright for components of this work owned by others than the Association for Information Systems must be honored. Abstracting with credit is permitted. To copy otherwise, to republish, to post on servers, or to redistribute to lists requires prior specific permission and/or fee. Request permission to publish from: AIS Administrative Office, P.O. Box 2712 Atlanta, GA, 30301-2712 Attn: Reprints or via e-mail from ais@aisnet.org. 